\title{
Correction to: Niche Partitioning among Snook (Pisces: Centropomidae) in Rivers of Southeastern Florida and Implications for Species Range Limits
}

Philip W. Stevens ${ }^{1} \cdot$ Jynessa Dutka-Gianelli ${ }^{1} \cdot$ Eric J. Nagid ${ }^{2} \cdot$ Alexis A. Trotter $^{1} \cdot$ Kevin G. Johnson $^{3} \cdot$ Travis Tuten $^{2} \cdot$ James A. Whittington ${ }^{4}$

Published online: 18 December 2019

(C) Coastal and Estuarine Research Federation 2019

\section{Correction to: Estuaries and Coasts.}

https://doi.org/10.1007/s12237-019-00650-x

In the original version of the article there was an error during the production of Fig. 3. The original article has been corrected and the corrected figure is as follows:

The online version of the original article can be found at https://doi.org/ 10.1007/s12237-019-00650-x

\footnotetext{
Philip W. Stevens

philip.stevens@myfwc.com
}

1 Florida Fish and Wildlife Conservation Commission, Fish and Wildlife Research Institute, St. Petersburg, FL, USA

2 Florida Fish and Wildlife Conservation Commission, Fish and Wildlife Research Institute, Gainesville, FL, USA

3 Florida Fish and Wildlife Conservation Commission, Fish and Wildlife Research Institute, Eustis, FL, USA

4 Florida Fish and Wildlife Conservation Commission, Tequesta Field Laboratory, Fish and Wildlife Research Institute, Tequesta, FL, USA 


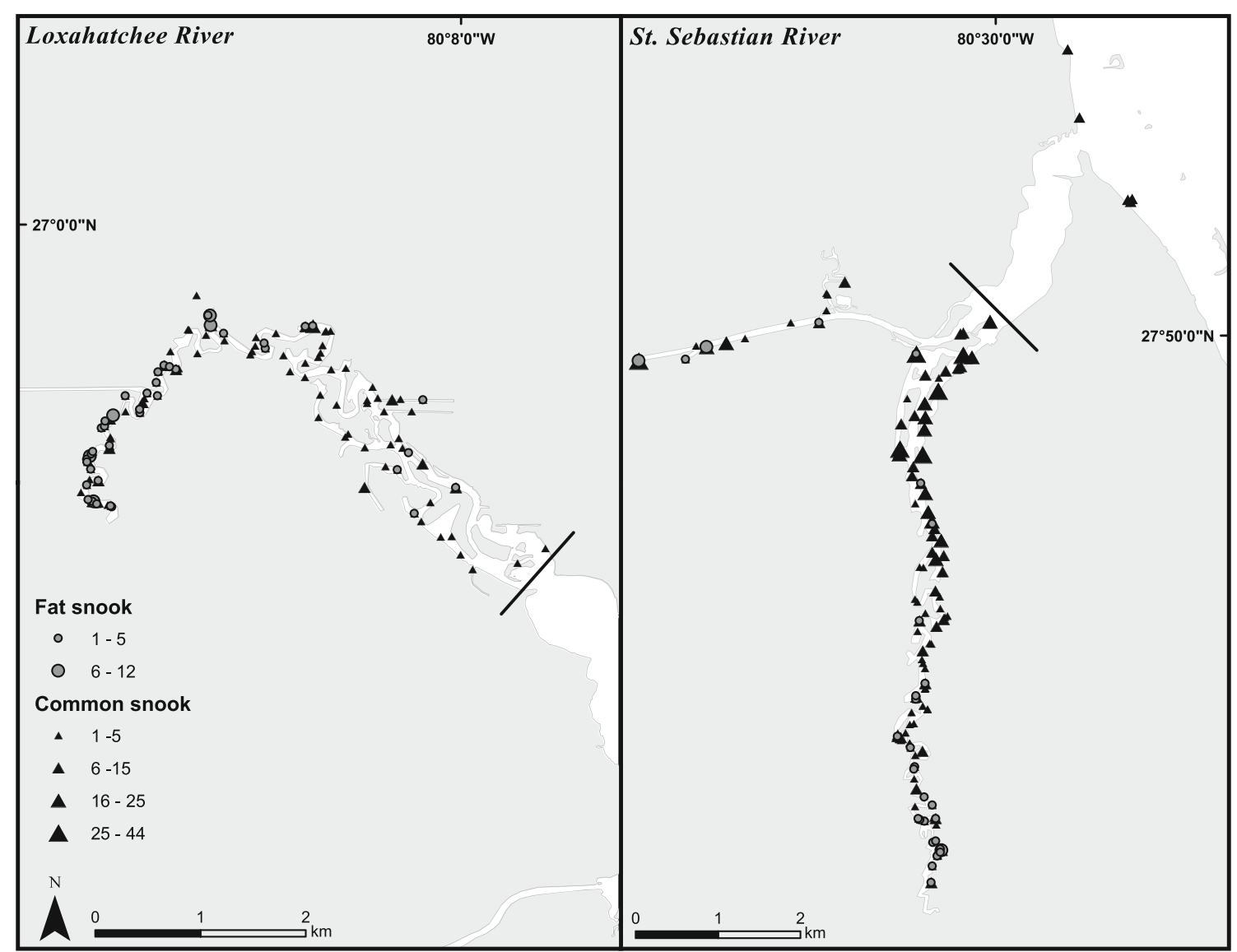

Fig. 3 Electrofishing captures (number per transect) of large-bodied (> $175 \mathrm{~mm} \mathrm{TL}$ ) common snook (triangles) and fat snook (circles) in the St Sebastian and Loxahatchee rivers. Also shown are capture locations of

snook using large haul seines along open estuarine shorelines of the Indian River Lagoon 